\title{
Misconceptions about Psychological Science: a review
}

\author{
SEAN HUGHES \& FIONA LYDDY \\ National University of Ireland, Maynooth, Ireland \\ SINEAD LAMBE \\ University of Bath, United Kingdom
}

\begin{abstract}
This article provides an overview of the available evidence on psychological misconceptions, including key findings, current directions and emerging issues for investigation. We begin by defining misconceptions and then examine their prevalence and persistence, discuss their implications for student learning and highlight potential strategies to eliminate or reduce their influence. Thereafter, several theoretical and methodological issues that have traditionally defined research in this area are discussed. In particular, we highlight the possibility that reported rates of misconceptions may in part be driven by particular features of the measurement procedures employed. On the basis of this analysis, potential avenues for future research are outlined.
\end{abstract}

Those students who come equipped to their studies with accurate pre-existing knowledge demonstrate greater understanding and retention of new information compared to those who harbour inaccurate or incomplete knowledge (Beier \& Ackerman, 2005; Thompson \& Zamboanga, 2003, 2004). Moreover, students who endorse disciplinary-inconsistent knowledge and beliefs often find their learning of new concepts impaired (Dochy, Segers, \& Buehl, 1999). Unfortunately, prior to setting foot in the classroom, many students already hold a spectrum of incorrect preconceptions about the core ideas and concepts relevant to their field of study - whether it is biology (Nehm \& Reilly, 2007), physics (Hein, 1999), or chemistry (Stefani \& Tsaparlis, 2009). Psychology is no exception to this phenomenon.

Misconceptions about psychological issues, such as 'Human memory works like a tape recorder or video camera', 'Handwriting can reveal our personality traits', and 'People with schizophrenia have multiple personalities', are widespread and often difficult to eliminate (Kowalski \& Taylor, 2009; Lilienfeld, Lynn, Ruscio, \& Beyerstein, 2009). Although misconceptions decrease as the number of psychology courses taken increases, upper-level undergraduates still accept a large variety of erroneous claims despite their training in the core concepts of the discipline (Glass, Bartels, Ryan, \& Stark-Wroblewski, 2008; Standing \& Huber, 2003). This is a cause for concern given that misconceptions are suggested to relate to academic performance (Kuhle, Barber \& Bristol, 2009; McCutcheon, 1991) as well as critical thinking ability (Kowalski \& Taylor, 2004). In this article we provide the reader with an overview of misconceptions about psychological science. We begin by defining misconceptions and discuss their various properties. We then examine their prevalence, their implications for student learning and various strategies for combating their influence. Several theoretical and methodological issues that have traditionally guided researchers in this area will also be evaluated. Finally, we highlight future work that may promote a better understanding of the factors that give rise to and propagate persistent misconceptions affecting our discipline. 


\section{What are Psychological Misconceptions?}

Different authors have employed a variety of nomenclatures, each based on a different set of assumptions about the nature and properties of discipline-inconsistent prior knowledge. Examples include preconceptions (Morrison \& Lederman, 2003), personal epistemologies (Hammer \& Elby, 2002), alternative conceptions (Piquette $\&$ Heikkinen, 2005), and naïve science (Pine, Messer, \& St John, 2001). Nevertheless, 'misconception' is the most frequently used term to describe knowledge and beliefs that are incongruent with the core concepts and empirical findings of a discipline (Hamza \& Wickman, 2008; Taylor \& Kowalski, 2004). With respect to psychology, statements such as 'People only use $10 \%$ of their brain', 'Most mentally ill people are violent', and 'Responses to inkblots tell us a great deal about our personalities', are often affirmed despite a lack of empirical support for these claims (Higbee \& Clay, 1998; Lenz, Ek, \& Mills, 2009; Phelan, Link, Stueve, \& Pescosolido, 2000). Other inaccuracies deeply ingrained in 'folk wisdom', such as 'A full moon causes strange or criminal behaviour', 'Opposites attract', or 'It is better to express anger than hold it in', are also seemingly endorsed by many (Brown, 1983; McCutcheon, 1991; Owens \& McGowan, 2006) (see Table 1 for an overview of ten popular misconceptions about psychological science).

Table 1. Popular psychological misconceptions endorsed by a majority of respondents.

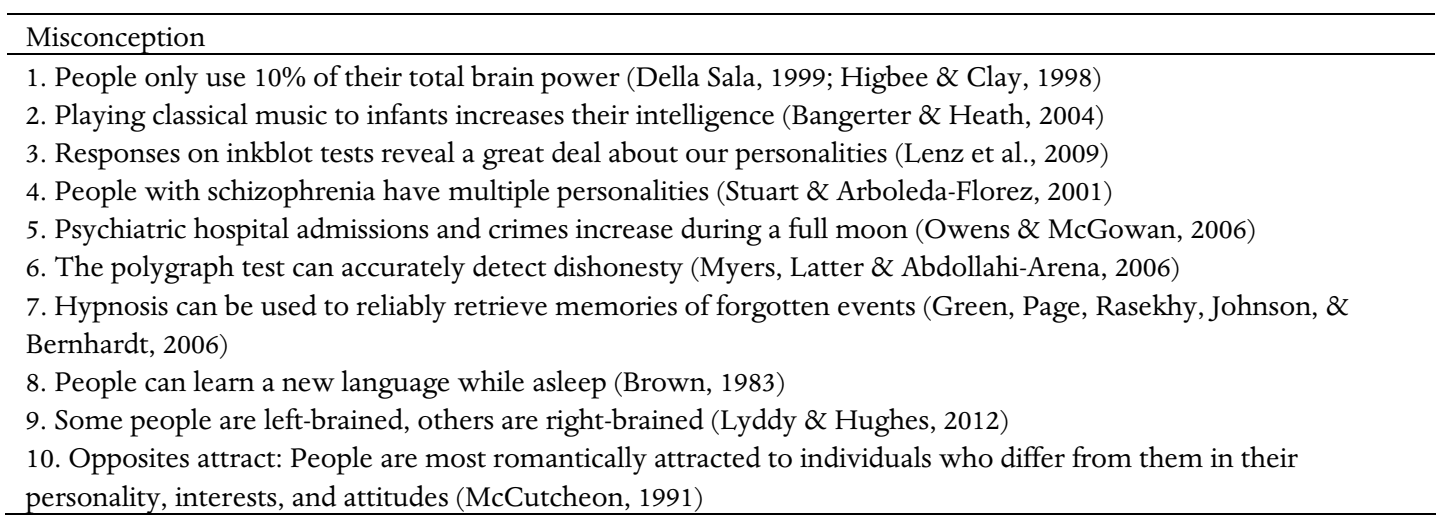

Misconceptions appear to stem from a variety of sources and may be broadly categorised into two groups. On the one hand, we define factual misconceptions as beliefs that arise from incorrect or incomplete information encountered in the popular media, classroom or the everyday environment. Claims such as 'Some people are left-brained, while others are right-brained', 'The polygraph test can accurately detect dishonesty', and 'Intelligence tests are biased against certain groups', are more likely to be derived from sources external to the individual rather than their own personal experiences.

On the other hand, we defined ontological misconceptions as those that reflect naïve or commonsense theories about thought, feelings and behaviour. Consider, for example, the emission theory of vision, the mistaken notion that people see by emitting, from their eyes, rays that reflect off objects. This notion is often affirmed by young children (Cottrell \& Winer, 1994) as well as college students (Winer, Cottrell, Karefilaki, \& Gregg, 1996), stretches all the way back to the ancient Greeks (Gross, 1999), and continues to influence cultural practices around the world (see Winer, Rader, \& Cottrell, 2003). While certainly influenced by the wider social context, it may be the case that this misconception (among others) is rooted in an underlying naïve ontology that differs dramatically from contemporary theory and research. In other words, several misconceptions may represent the outcome of a collection of ontological assumptions, explanatory concepts and causal mechanisms that, when taken together, form the basis of intuitive theories about psychology (Amsel, Baird, \& Ashley, 2011). For instance, the common belief in mind-body dualism (Bloom, 2004) may propagate a variety of misconceptions surrounding extrasensory perception, memories of previous lives and 'out-of-body experiences' (Lilienfeld et al., 2009). Thus in the same way that people may harbour commonsense theories of motion (Reiner, Slotta, Chi, \& Resnick, 2000), or about life (Carey, 1985), it is also possible for misconceptions to be rooted in 
intuitive theories about the mind, cognitive illusions (Pohl, 2004), or even heuristics (Schick \& Vaughn, 2010). As we shall see later, this distinction between factual and ontological misconceptions may be an important one, especially when it comes to developing strategies to undermine or eliminate them.

Regardless of the type of misconception involved, three questions have guided empirical and theoretical work in this research area. First, a majority of studies have attempted to document how prevalent misconceptions are in both psychology students and the wider population. Second, in light of their apparent resistance to extinction, the potential implications of holding misconceptions for academic outcomes and critical thinking development has increasingly been explored. Finally, given that misconceptions are responsive to correction when certain conditions are met, a number of theoretical accounts have been offered to explain when and why this change occurs. In the following sections, we provide a brief review of the relevant literature for each of these three questions.

\section{Prevalence and Origins of Psychological Misconceptions}

The study of psychological misconceptions has constituted a recognisable research enterprise for more than eighty years now, with the general public (Furnham, Callahan, \& Rawles, 2003; Green, Page, Rasekhy, Johnson, \& Bernhardt, 2006), educators (Gardner \& Hund, 1983), as well as undergraduate and graduate students, all found to harbour a number of inaccurate beliefs about the discipline and its subject matter (Arntzen, Lokke, Lokke, \& Eilertsen, 2010; Vaughan, 1977). Research has predominantly focused on undergraduate (introductory) students whose endorsement of misconceptions has been found to vary from $28 \%$ to $71 \%$ agreement across studies (see Lilienfeld et al., 2009). Such large variations may in part reflect sampling differences (Kuhle et al., 2009), as well as methodological issues surrounding the measurement procedures employed in this area (Hughes, Lyddy, \& Kaplan, 2013). At the same time, students' endorsement of misconceptions also differs with the amount of disciplinary training they have received (Gardner $\&$ Dalsing, 1986; Lamal, 1995), and their critical thinking ability (Kowalski \& Taylor, 2004). Nevertheless, misconceptions appear to reflect a genuine and general phenomenon concerning core beliefs about the discipline (e.g., 'Research conducted in controlled laboratory settings is not essential for understanding everyday behaviour'), as well as specific disciplinary information (e.g., 'The polygraph test is an accurate detector of lies').

Although much work has focused on the prevalence of psychological misconceptions, less attention has been devoted to understanding how people come to acquire or develop them. Several authors suggest that misconceptions stem from exposure to inaccurate information reinforced in the popular media, or instruction and textbooks that present an oversimplification of concepts (Stanovich, 2009). For instance, Taylor and Kowalski (2004) found that students attribute $20 \%$ of their misconceptions to the media, $19 \%$ to personal experience, $16 \%$ to reading, and $15 \%$ to classroom learning (see also Higbee \& Clay, 1998). Similarly, 38\% of students reported that their misconceptions emerged directly as a result of one of their psychology courses or instructors (Landau \& Bavaria, 2003). While potentially informative, the reliability of these self-reported 'sources of misconceptions' will need to be addressed in further detail.

Misconceptions have also been argued to reflect cognitive biases such as confirmatory bias, illusory correlations, a tendency to infer causation from correlation, post hoc ergo propter hoc reasoning, as well as exposure to selective samples (Lilienfeld et al., 2009; Schick \& Vaughn, 2010). Still others argue that misconceptions do not reflect inaccurate or incomplete prior beliefs, but rather a core set of explanatory concepts that people use to understand, predict and influence behaviour (termed 'folk psychology'; Amsel et al., 2011). It is worth noting, however, that these environmental and cognitive factors have generally been supported more by argument than empirical evidence (Chew, 2006). Consequently, future work will need to systematically examine their independent or combined role in the formation and persistence of misconceptions. Such an analysis would serve to strengthen existing claims about the origin of misconceptions, and aid the development of teaching techniques that aim to prevent or combat their influence. 


\section{Persistence of Psychological Misconceptions and their Implications for Learning}

Misconceptions are argued to pose a challenge to educators for three reasons. First, they appear to be highly resistant to extinction, with standard instructional strategies (i.e., presenting information supported by evidence with the assumption that students will critically evaluate that material) insufficient to effectively combat them. Exposure to an introductory psychology course - or even a number of courses - has been found to reduce several misconceptions but fails to eliminate many others (Gregg, Winer, Cottrell, Hedman, \& Fournier, 2001; Lamal, 1995; Landau \& Bavaria, 2003). For example, $30 \%$ of students who have completed several psychology courses still agree that someone experiencing schizophrenia has a 'split personality' (Gardner \& Dalsing, 1986), and that 'Most people only use $10 \%$ of their potential brain power' (Higbee \& Clay, 1998). Therefore it appears that students come to their studies with a variety of misconceptions, and often leave with many of them intact. Providing factual knowledge with the expectation that students will critically evaluate psychological claims appears to be inadequate for correcting discipline-inconsistent beliefs.

Second, not only are misconceptions resistant to normal teaching practices, they have also been suggested to impact negatively on the learning of new information. Note again, however, that this assumption has largely been driven by theoretical conjecture (Chew, 2006; Hammer, 1996; Posner, Strike, Hewson, \& Gertzog, 1982), with research yielding less than conclusive findings in this respect. On the one hand, misconception endorsement has been found to negatively correlate with academic performance (e.g., Kuhle et al., 2009. See also Amsel et al., 2009; McCutcheon, 1991), and higher performing students are also more likely to relinquish misconceptions following instruction relative to their low-performing counterparts (Gutman, 1979). On the other hand, a number of studies have failed to obtain any direct or conclusive relationship between academic performance and susceptibility to misconceptions when other variables such as disciplinary training, cumulative attendance (Thompson $\&$ Zamboanga, 2004), or homework scores (Kowalski $\&$ Taylor, 2004) are explicitly controlled for (Best, 1982; Vaughan 1977). Clearly, further work is needed to separate out the unique contribution of misconceptions from other relevant variables in determining whether and in what way they affect learning.

Finally, a tendency to affirm misconceptions may signal the need for additional critical thinking training. The term 'critical thinking' can be defined in a variety of ways and can be used to refer to a number of related skills. Halpern (2007) defines critical thinking as 'thinking that is purposeful, reasoned and goal directed - the kind of thinking involved in solving problems, formulating inferences, calculating likelihoods, and making decisions' (p. 6). We refer to critical thinking as the disposition and ability to retrieve and use information to evaluate knowledge claims with the goal of generating sound conclusions from that information in a trans-contextual fashion. It includes the tendency to question whether there is evidence to support a particular claim. Developing a disposition for and success in applying critical thinking may be crucial for students, given that it appears to serve as predictor for academic success as well as misconception endorsement. For instance, students who demonstrate sophisticated critical thinking are - all things being equal - more likely to attain better grades than their counterparts with less sophisticated critical thinking skills, while students who attain good grades are also more likely to improve their critical thinking abilities relative to those who perform less well (Williams, Oliver, \& Stockdale, 2004). Moreover, students who actively employ critical thinking skills to evaluate newly encountered information also appear to be less susceptible to misconceptions about the discipline (Kowalski \& Taylor, 2004). As we shall see in the next section, however, caution must be exercised when inferring a causal link between academic performance, critical thinking and misconception endorsement, especially in the absence of experimental or intervention studies that directly manipulate the latter two variables.

\section{Correcting Misconceptions about Psychological Science}

\section{Teaching Strategies}

Given that misconceptions often persist in the face of standard instruction and may hinder student learning, a key question concerns how to combat them. Initial work has focused on the roles of source monitoring (i.e., asking students to carefully scrutinise the sources of their misconceptions; 
Landau \& Bavaria, 2003), refutational teaching strategies and critical thinking (Kowalski \& Taylor, 2004). Consider teaching strategies: although misconceptions are often resistant to correction via standard instruction, refutational readings (Guzzetti, 2000), essays (Miller, Wozniak, Rust, Miller, \& Slezak, 1996), lectures or some combination of the three (Kowalski \& Taylor, 2009) have met with success in eliminating them. In each case, a misconception is first highlighted and then directly refuted using empirical evidence. Vaughan (1977) found that although the introductory course had only a minimal impact upon student misconceptions (6.5\% reduction), erroneous beliefs that did change were those that had been directly refuted during the course. Likewise, when the effectiveness of refutational text and lectures was compared to a standard lecture and text combination (or no coverage of the misconceptions at all), the refutational approach was superior in dispelling these beliefs (Kowalski \& Taylor, 2009). Moreover, refutational lectures alone produced a significant reduction in misconceptions above and beyond that contributed by the refutational text. This preliminary work highlights that psychology instructors should tailor their teaching strategies towards (a) explicitly identifying misconceptions to their students and then (b) directly refuting them through lectures and readings. At the same time, alternative teaching techniques may also provide a means for correcting student misunderstandings. Mazur (1997) developed a teaching tool termed ConcepTest as a means to activate and then correct misconceptions using a multiple-choice format (see Chew, 2004, for its application to psychology). Amsel (2009) argues for the need to go beyond knowledge transmission in teaching psychology and advocates meta-instruction - teaching that aims to convey psychology's beliefs and values and to transform students' identities as future members of the scientific community.

\section{Critical Thinking}

Although little work has investigated the interaction between misconceptions, academic performance and critical thinking, the latter variable may play a role in reducing inaccurate beliefs. McCutcheon, Apperson, Hanson, \& Wynn (1992) found that while both course grades and critical thinking independently predicted misconception endorsement, critical thinking was a significantly better predictor. Likewise, Kowalski and Taylor (2004) found no relation between students' academic performance and susceptibility to misconceptions prior to an introductory psychology course, suggesting that both high- and low-performing students arrive at the discipline with misunderstandings about its core concepts. Following the course, however, significant correlations were observed between course grades, critical thinking ability and changes in misconceptions, with the effect of academic performance moderated by its relation to critical thinking. Irrespective of academic performance, those students who actively employed critical thinking skills to evaluate newly encountered information were less susceptible to misconceptions.

Importantly, these findings may also clarify the ambiguous relationship between academic performance and misconception endorsement noted previously. In other words, both variables could be moderated by a third factor that was uncontrolled for in the aforementioned studies (i.e., critical thinking). To examine this issue further, future research could examine whether training aimed at improving critical thinking results in similar reductions in misconceptions for both lowand high-performing students. Similarly, little work has directly compared whether generic versus subject-specific critical thinking is a better predictor of academic performance and misconception endorsement. For instance, will students who are specifically trained to think sceptically about psychological theory and research also apply those skills to other intellectual domains and everyday life (e.g., when evaluating advertisements, political propaganda or new medicines)?

\section{Temporary or Permanent Changes in Misconceptions?}

Although misconceptions may be successfully eliminated, the possibility remains that any such change may only be temporary in nature. Consistent with this notion, Winer, Cottrell, Gregg, Fournier, \& Bica (2002) reviewed a series of studies on the emission theory of vision. Although a highly simplified lecture on vision containing refutational statements reduced erroneous beliefs, those same mistaken beliefs re-emerged five months later (see also Landau \& Bavaria, 2003). This may be an important issue given that many - if not most - misconception studies have employed 
either a single test or a pre-post design to probe for changes immediately following a course or manipulation. When such a strategy is adopted, researchers and educators alike may inadvertently view misconceptions as being successfully eliminated. Yet it is possible that a 'rebound effect' may occur whereby inaccuracies addressed within a single class or course are temporarily reduced but nevertheless re-emerge once course content moves on to other areas (Lyddy \& Hughes, 2012). Put differently, when researchers introduce a manipulation to reduce misconceptions, and then test the effectiveness of that manipulation within a single class or course, it is not possible to know with certainty that misconceptions have truly been eliminated across time and context. Consequently, future research will need to adopt a longitudinal assessment of misconceptions to ascertain the degree and duration of change long after the course has ended. It should also be noted that the majority of research in this area has focused solely on undergraduate (introductory) psychology students. A detailed picture of the prevalence and transmission of misconceptions at all levels of the discipline will only emerge by directing attention towards graduate students and university-level educators as well as introductory or advanced undergraduates.

\section{Methodological Issues in the Study of Psychological Misconceptions}

As outlined above, the degree to which people purportedly fall prey to psychological misconceptions varies significantly from study to study. These large variations could reflect methodological issues surrounding the procedures commonly employed in this research domain (Brown, 1984; Griggs \& Ransdell, 1987; Ruble, 1986). Specifically, although numerous techniques have been devised to measure misconceptions, including computerised assessment (Gregg et al., 2001), interviews (Hamza \& Wickman, 2008), open-ended questions (Klymkowsky \& GarvinDoxas, 2008), and concept-mapping (Liu, Lin, \& Tsai, 2009), psychological research has almost exclusively relied on self-report questionnaires. More often than not this involves participants registering their (dis)agreement with a series of statements using a dichotomous true/false response format. Recently, however, many of these questionnaires have come under criticism due to the ambiguity of test items and response format used.

One criticism concerns the ambiguity or lack of precision associated with certain test items, such that participants may interpret the same question in different ways. Where this is the case, misconception questionnaires may be subject to response biases above and beyond the application of faulty beliefs and knowledge. For illustration purposes, consider the following claim: 'Most people use only $10 \%$ of their potential brain power'. When phrased in this manner as many as $77 \%$ of students agree with this statement (Landau \& Bavaria, 2003). Yet when asked 'What percentage of their potential brain power do you think most people use' and given 21 different choices ranging from $0 \%$ to $100 \%$, acceptance of the $10 \%$ myth varies from $5 \%$ to $90 \%$ (Higbee \& Clay, 1998). Indeed, the difficulty with devising a list of specific and unambiguous erroneous statements has been noted throughout the literature. Griggs and Ransdell (1987) conducted a review of several studies assessing psychological misconceptions and identified 21 items that were consistently employed across studies despite concerns about their ambiguity. A second criticism surrounds the response format typically employed in misconception questionnaires. Given the complexity of psychological phenomena and the fact that empirical findings are often subject to further qualification, restricting responses to 'true' or 'false' may be problematic for two reasons. On the one hand, many misconceptions may be partially incorrect but not entirely false. They may contain a 'kernel of truth' or be true some of the time, but not generally. Consider the notion that 'opposites attract'. Although small differences between romantic partners may contribute to a more interesting and varied relationship, we typically select mates that are similar to ourselves in personality, attitudes and values (e.g., Buston \& Emlen, 2003; Hitsch, Hortaçsu, \& Ariely, 2009). Gardner and Hund (1983) found that when they asked (non)social science faculty to register their (dis)agreement with a series of statements using a 5-point scale, the majority of misconceptions were rated as 'mostly false' rather than 'completely false', and several misconceptions as 'partly false' or 'partly true'. On the other hand, it may also be the case that the true/false format fails to distinguish between strongly held misconceptions and responses due to uncertainty or guessing. For instance, including an 'I don't know/no opinion' option in a 60 -item true-false misconception 
questionnaire resulted in students reporting uncertainty for $12 \%$ of responses (Gardner $\&$ Dalsing, 1986).

To circumvent these problems, multiple-choice scales have increasingly been used to sensitively discriminate the direction and relative strength of the belief, as well as to register responses due to uncertainty or guessing (Assanand, Pinel, \& Lehman, 1998; McCutcheon, 1991). Others have also argued for the inclusion of procedures that capture how confident students are in their misconceptions. Taylor and Kowalski (2004) constructed a 48-item true/false questionnaire but also included a 1-10 confidence scale in order to assess the strength of students' prior beliefs. Following an introductory course (employing a refutational format), correct identification of misconceptions nearly doubled. In addition, rated confidence for accurate beliefs increased, whereas confidence for misconceptions that students still endorsed decreased. This suggests that confidence ratings may provide an index of misconceptions that are retained but are in the process of changing. If this is the case, then inaccurate beliefs may change in degree rather than kind. Although admittedly speculative, misconception correction may be a gradual developmental process rather than a sudden and revolutionary one.

To conclude, an accurate and sensitive index of psychological misconceptions requires that the procedures used are subject to careful scrutiny. Future work will need to determine whether the language and structure of self-report questionnaires affect the degree to which students affirm misconceptions. Doing so would serve to identify differences in misconceptions that arise not from the application of faulty knowledge and beliefs but as a result of the measure employed (see Hughes et al., 2013). At the same time, research will need to ascertain the utility of alternative procedures above and beyond self-report questionnaires. Towards this end, future work could import novel methods from other disciplines and compare performance on these tasks against existing questionnaires. Adopting such a strategy would enable educators to better identify legitimate methods of assessing their students' knowledge and beliefs. Finally, the potential influence of demand-compliance or self-presentation effects may also require attention, given that participants may be alert to the fact that such questionnaires target popular misconceptions. Although several authors have included filler items to mask their intended manipulation (Kowalski \& Taylor, 2009), the majority of studies have not. Further research will need to systematically manipulate the presence versus absence of filler items, or even cover stories to determine their influence on task performance.

\section{Theoretical Models for Correcting Misconceptions}

A number of theoretical accounts have been offered to explain: (a) how misconceptions should be conceptualised; (b) why they are resistant to correction; and (c) the necessary conditions for successful learning (see Booth \& Koedinger, 2008; Hammer \& Elby, 2002; Reif, 1995). Of these models, conceptual change currently represents the dominant theoretical position in the literature (Limón \& Mason, 2002). Within this perspective, the precise conceptualisation of 'conceptual change' varies from model to model. For example, Vosniadou (2008) argues that misconceptions are a product of well-established ontological assumptions, concepts, and causal mechanisms that people use to formulate an intuitive or 'naive' theory of human behaviour. These theories are employed and reinforced continuously through interaction with the lay culture, making misconceptions resistant to quick or easy revision. Alternatively, Chi and Roscoe (2002) view misconceptions as the ontological mis-categorisation of concepts and conceptual change as the repair (or reassignment) of incorrect concepts to their correct categories. Finally, Ivarsson, Schoultz, and Säljö's (2002) sociocultural model treats misconceptions as the by-product of a lack of discipline-specific training in the appropriate use of its 'intellectual tools' (i.e., agreed-upon concepts as well as means of communicating). According to this perspective, conceptual change involves the gradual socialisation into and effective use of the tools of the discipline. Although the aforementioned accounts differ in their approach to conceptual change, they each share one common assumption: misconceptions can only be corrected by revising or restructuring currently held inaccurate beliefs towards disciplinary consistent knowledge. When prior knowledge and beliefs are consistent with new information, learning is facilitated. However, when prior knowledge and beliefs contradict newly acquired information, learning is impaired. Therefore 
successful learning results only when students critically evaluate previously held beliefs as well as revise and replace them with new and disciplinary consistent information. Given that it is easier for people to ignore, reinterpret, or reject new information rather than to revise their existing beliefs, conceptual change requires four conditions to be met: (1) students must be motivated (i.e., dissatisfied with their prior belief); (2) the alternative explanatory concept must be intelligible (meaningful and non-contradictory); (3) the alternative concept must be plausible (believable to the student); and (4) the alternative concept must be useful (aids the student in solving problems) (see Treagust \& Duit, 2008). This 're-evaluation' process is assumed to occur when teaching purposefully 'activates' prior knowledge and then creates a cognitive conflict between that knowledge and the information to be learned. In contrast to their ontological counterparts, factual misconceptions may not require that a rich network of assumptions, explanatory concepts and causal mechanisms be examined, modified and restructured. Rather, and as noted in the introduction, these inaccuracies usually reflect faulty or incorrect information contacted through exposure to the media and popular culture. Consequently, correcting claims such as 'People with schizophrenia have multiple personalities', 'Playing Mozart to babies increases their intelligence', or 'There has recently been a massive epidemic of infantile autism', may not involve conceptual change - at least as defined above. Instead, factual misconceptions may be undermined or even eliminated via refutational teaching practices that alert students to their mistaken beliefs while providing relevant, accurate information about the topic of concern. In doing so, these techniques may create a 'cognitive conflict' between the old and new knowledge, while also providing coherent and credible accounts for the student to adopt. A revision of the misconception may subsequently take place when the student is dissatisfied with their prior belief and the newly presented information is construed as intelligible, plausible, and useful (see Kowalski \& Taylor, 2009). Despite a wealth of theoretical work in this area, several questions require attention. On the one hand, research on conceptual change and its mediating role in the reduction of misconceptions has largely been correlational in nature. Further insight into the causal role of conceptual change in misconception revision awaits research that (a) clearly operationalises this construct, and (b) demonstrates that indirectly manipulating this variable produces concomitant changes in misconceptions. On the other hand, future research will also need to determine whether carving misconceptions into factual and ontological varieties has useful implications for educational researchers and instructors alike. For example, are the strategies necessary for undermining factual misconceptions also successful in targeting ontological misconceptions? Is it the case that changes in misconceptions reflect the ability to sceptically evaluate and modify naïve theories of psychology or simply the capacity to answer specific questions that have been directly instructed during a course?

\section{Conclusion}

Students do not arrive to the study of psychological science as blank slates but rather come equipped with varying amounts of (inaccurate) knowledge and beliefs. Although the reported prevalence of misconceptions about psychology is subject to large variation across studies, these inaccuracies appear to reflect a genuine, replicable and general phenomenon. Several authors have theorised that these erroneous beliefs have negative consequences for student learning; however there is no conclusive agreement on this issue to date. Nevertheless, misconceptions appear highly resistant to standard classroom instruction, such that many students may leave both introductory and more advanced psychology courses equipped with a host of inaccurate beliefs. Although difficult to change, misconceptions can be corrected when instructors highlight not only what is correct or empirically verified, but also what is incorrect and empirically unsupported.

Documenting how readily students affirm inaccuracies about the discipline constitutes a necessary first step - but only a first step. A more detailed picture will emerge only by addressing whether and why misconceptions constitute a serious impediment for critical thinking or learning more generally. Likewise, are misconceptions present at all levels of the discipline (e.g., graduate students and faculty members), and are they moderated by cultural factors? Is the tendency to affirm misconceptions trans-contextual, such that those students who readily affirm psychological misconceptions are also more likely to agree with erroneous medical, consumer or political claims? 
Although refutation instruction has met with success in dispelling misconceptions, what impact would a critical thinking course, that explicitly equips students with a set of intellectual tools, have for rejecting erroneous claims? In answering these and related questions, future work will need to pay careful attention to methodological issues surrounding core properties of misconception questionnaires. Only by doing so will we identify the factors responsible for shaping, maintaining and extinguishing misconceptions about our discipline.

\section{References}

Amsel, E. (2009). Teaching psychology students to think like psychologists. Proceedings of the Fifth Annual Science Education at the Crossroads Conference, September 20-22, 2009. Retrieved March 12010 from http: / / faculty.weber.edu/ eamsel/Research/Papers / Crossroads\%202009.pdf

Amsel, E., Baird, T., \& Ashley, A. (2011). Misconceptions and conceptual change in undergraduate students learning psychology. Psychology Learning and Teaching, 10(1), 3-10. http: / / dx.doi.org/10.2304/ plat.2011.10.1.3

Amsel, E., Johnston, A., Alvarado, E., Kettering, J., Rankin, R., \& Ward, M. (2009). The effect of perspective on misconceptions in psychology: A test of conceptual change theory. Journal of Instructional Psychology, 36(4), 289-295.

Arntzen, E., Lokke, J., Lokke, G., Eilertsen, D. E. (2010). On misconceptions about behaviour analysis among university students and teachers. The Psychological Record, 60(2), 325-336.

Assanand, S., Pinel, J. P., \& Lehman, D. R. (1998). Teaching theories of hunger and eating: Overcoming students' misconceptions. Teaching of Psychology, 25(1), 44. http:/ / dx.doi.org/10.1207/s15328023top2501_14

Bangerter, A., \& Heath, C. (2004). The Mozart effect: Tracking the evolution of a scientific legend. British Journal of Social Psychology, 43, 605-623. http: / dx.doi.org/10.1348/0144666042565353

Beier, M. E., \& Ackerman, P. L. (2005). Age, ability, and the role of prior knowledge on the acquisition of new domain knowledge: Promising results in a real-world learning environment. Psychology and Aging, 20, 341-355. http:/ / dx.doi.org/10.1037/0882-7974.20.2.341

Best, J. B. (1982). Misconceptions about psychology among students who perform highly. Psychological Reports, 51, 239-244. http:// dx.doi.org/10.2466/pr0.1982.51.1.239

Bloom, P. (2004). Descartes' baby. New York: Basic Books.

Booth, J. L., \& Koedinger, K. R. (2008). Key misconceptions in algebraic problem solving. In B. C. Love, K. McRae, \& V. M. Sloutsky (Eds.), Proceedings of the 30th Annual Conference of the Cognitive Science Society, 571-576.

Brown, L. T. (1983). Some more misconceptions about psychology among introductory psychology students. Teaching of Psychology, 10, 207-210. http:/ / dx.doi.org/10.1207/s15328023top1004_4

Brown, L. T. (1984). Misconceptions about psychology aren't always what they seem. Teaching in Psychology, 11, 75-78. http:/ / dx.doi.org/10.1207/s15328023top1102_3

Buston, P. M., \& Emlen, S. T. (2003). Cognitive processes underlying human mate choice: The relationship between self-perception and mate preference in Western society. Proceedings of the National Academy of Sciences, 100, 8805-8810. http:/ / dx.doi.org/10.1073/pnas. 1533220100

Carey, S. (1985). Conceptual change in childhood. Cambridge, MA: MIT Press.

Chew, S. L. (2004). Student misconceptions in the psychology classroom. Essays from Excellence in Teaching, Vol. 4. Retrieved August 16, 2012, from http:/ teachpsych.org/resources/e-books/ eit2004/eit04-03.pdf.

Chew, S. L. (2006). Seldom in doubt but often wrong: Addressing tenacious student misconceptions. In D. S. Dunn \& S. L. Chew (Eds.), Best practices for teaching introduction to psychology (pp. 211-223). Mahwah, NJ: Erlbaum.

Chi, M. T. H., \& Roscoe, R. D. (2002). The process and challenges of conceptual change. In M. Limón \& L. Mason (Eds.), Reconsidering conceptual change: Issues in theory and practice. Dordrecht, The Netherlands: Kluwer Academic. http:/ / dx.doi.org/10.1007/0-306-47637-1_1

Cottrell, J. E., \& Winer, G. A. (1994). Development in the understanding of perception: The decline of extramission perception beliefs. Developmental Psychology, 30, 218-228. http: / / dx.doi.org/10.1037/0012-1649.30.2.218

Della Sala, S. (Ed.). (1999). Mind myths: Exploring popular assumptions about the mind and brain. Chichester: Wiley. 
Dochy, F., Segers, M., \& Buehl, M. M. (1999). The relation between assessment practices and outcomes of studies: The case of research on prior knowledge. Review of Educational Research, 69(2), 145-186.

Furnham, A., Callahan, I., \& Rawles, R. (2003). Adults' knowledge of general psychology. European Psychologist, 8, 101-116. http:/ / dx.doi.org/10.1027/ / 1016-9040.8.2.101

Gardner, R. M., \& Dalsing, S. (1986). Misconceptions about psychology among college students. Teaching of Psychology, 13, 32-34. http:/ / dx.doi.org/10.1207/s15328023top1301_9

Gardner, R. M., \& Hund, R. M. (1983). Misconceptions of psychology among academicians. Teaching of Psychology, 10, 20-22. http:/ / dx.doi.org/10.1207/s15328023top1001_5

Glass, L., Bartels, J., Ryan, J., \& Stark-Wroblewski, K. (2008). The effectiveness of psychology courses at discontinuing common psychological myths. Individual Differences Research, 6(2), 97-103.

Green, J. P., Page, R. A., Rasekhy, R., Johnson, L. K., \& Bernhardt, S. E. (2006). Cultural views and attitudes about hypnosis: A survey of college students across four countries. International Journal of Clinical and Experimental Hypnosis, 54, 263-280. http:/ / dx.doi.org/10.1080/00207140600689439

Gregg, V. R., Winer, G. A., Cottrell, J. E., Hedman, K. E., \& Fournier, J. S. (2001). The persistence of a misconception about vision after educational interventions. Psychonomic Bulletin \& Review, 8, 622-626. http: / / dx.doi.org/10.3758/BF03196199

Griggs, R. A., \& Ransdell, S. E. (1987). Misconceptions tests or misconceived tests? Teaching of Psychology, 14, 210-214. http://dx.doi.org/10.1207/s15328023top1404_4

Gross, C. G. (1999). The fire that comes from the eye. The Neuroscientist, 5, 58-64. http: / / dx.doi.org/10.1177/107385849900500108

Gutman, A. (1979). Misconceptions of psychology and performance in the introductory course. Teaching in Psychology, 6, 159-161. http:/ / dx.doi.org/10.1207/s15328023top0603_9

Guzzetti, B. J. (2000). Learning counter-intuitive science concepts: What have we learned from over a decade of research? Reading and Writing Quarterly, 16, 89-98. http: / / dx.doi.org/10.1080/105735600277971

Halpern, D. F. (2007). The nature and nurture of critical thinking. In R. J. Sternberg, H. L. Roediger \& D. F. Halpern (Eds.), Critical thinking in psychology (pp. 1-14). Cambridge: Cambridge University Press.

Hammer, D. (1996). More than misconceptions: Multiple perspectives on student knowledge and reasoning, and an appropriate role for education research. American Journal of Physics, 64, 1316-1325. http:/ / dx.doi.org/10.1119/1.18376

Hammer, D., \& Elby, A. (2002). On the form of a personal epistemology. In B. K. Hofer \& P. R. Pintrich (Eds.), Personal epistemology: The psychology of beliefs about knowledge and knowing (pp. 169-190). Mahwah, NJ: Lawrence Erlbaum.

Hamza, K. M., \& Wickman, P. (2008). Describing and analyzing learning in action: an empirical study of the importance of misconceptions in learning science. Science Education 92, 141-164. http: / / dx.doi.org/10.1002/sce.20233

Hein, T. L. (1999). Using writing to confront student misconceptions in physics. European Journal of Physics, 20, 137-141. http: / / dx.doi.org/10.1088/0143-0807/20/3/002

Higbee, K. L., \& Clay, S. L. (1998). College students' beliefs in the ten-percent myth. Journal of Psychology, 132(5), 469-476. http:/ / dx.doi.org/10.1080/00223989809599280

Hitsch, G. J., Hortaçsu, A., \& Ariely, D. (2010). What makes you click? Mate preferences in online dating. Quantitative Marketing and Economics, 8, 393-427. doi:10.1007/s11129-010-9088-6.

Hughes, S., Lyddy, F., \& Kaplan, R. (2013). The impact of language and response format on student endorsement of psychological misconceptions. Teaching of Psychology, 40(1), 31-37. http: / / dx.doi.org/10.1177/0098628312465861

Ivarsson, J., Schoultz, J., \& Säljö, R., (2002). Map reading versus mind reading: Revisiting children’s understanding of the shape of the earth. In M. Limón \& L. Mason (Eds.), Reconsidering conceptual change: Issues in theory and practice. Dordrecht, The Netherlands: Kluwer Academic. http:/ / dx.doi.org/10.1007/0-306-47637-1_4

Klymkowsky, M. W., Garvin-Doxas, K. (2008). Recognizing student misconceptions through Ed's tools and the biology concept inventory. PLoS Biology, 6, 14-17. http:/ / dx.doi.org/10.1371/journal.pbio.0060003

Kowalski, P., \& Taylor, A. (2004). Ability and critical thinking as predictors of change in students' psychological misconceptions. Journal of Instructional Psychology, 31(4), 297-303.

Kowalski, P., \& Taylor, A. (2009). The effect of refuting misconceptions in the introductory psychology class. Teaching of Psychology, 36, 153-159. http: / / dx.doi.org/10.1080/00986280902959986 
Kuhle, B. X., Barber, J. M., \& Bristol, A. S. (2009). Predicting students' performance in introductory psychology from their psychology misconceptions. Journal of Instructional Psychology, 36(2), 119-124.

Lamal, P. A. (1995). College students' misconceptions about behavior analysis. Teaching of Psychology, 22, 177-179. http://dx.doi.org/10.1207/s15328023top2203_3

Landau, J. D., \& Bavaria A. J. (2003). Does deliberate source monitoring reduce students' misconceptions about psychology? Teaching of Psychology, 30, 311-314.

Lenz, M. A., Ek, K., \& Mills, A. C. (2009). Misconceptions in psychology. Presentation at the 4th Midwest Conference on Professional Psychology, Owatonna, MN.

Lilienfeld, S. O., Lynn, S. J., Ruscio, J., \& Beyerstein, B. L. (2009). Fifty great myths of popular psychology: Shattering widespread misconceptions about human behavior. Chichester, UK: Wiley-Blackwell.

Limón, M., \& Mason, L. (Eds.). Reconsidering conceptual change: Issues in theory and practice. Dordrecht, The Netherlands: Kluwer Academic

Liu, T. C., Lin, Y., \& Tsai, C. (2009). Identifying senior high school students' misconceptions about statistical correlation, and their possible causes: An exploratory study using concept mapping with interviews. International Journal of Science and Mathematics Education, 7(4), 791-820. http:/ / dx.doi.org/10.1007/s10763-008-9142-y

Lyddy, F., \& Hughes, S. (2012). Attitudes towards psychology as a science and the persistence of psychological misconceptions in psychology undergraduates. In V. Karandashev \& S. McCarthy (Eds.), Teaching psychology around the world (Vol. 3). Newcastle upon Tyne, UK: Cambridge Scholars Publishing.

Mazur, E. (1997). Peer instruction: A user's manual. Englewood Cliffs, NJ: Prentice Hall.

McCutcheon, L. E. (1991). A new test of misconceptions about psychology. Psychological Reports, 68, 647-653. http: / / dx.doi.org/10.2466/pr0.1991.68.2.647

McCutcheon, L. E., Apperson, J. M., Hanson, E., \& Wynn, V. (1992). Relationships among critical thinking skills, academic achievement, and misconceptions about psychology. Psychological Reports, 71, 635-639.

Miller, R. L., Wozniak, W. J., Rust, M. R., Miller, B. R., \& Slezak, J. (1996). Counterattitudinal advocacy as a means of enhancing instructional effectiveness: How to teach students what they do not want to know. Teaching of Psychology, 23(4), 215-219. http:/ / dx.doi.org/10.1207/s15328023top2304_2

Morrison, J. A., \& Lederman, N. G. (2003). Science teachers' diagnosis of understanding of students' preconceptions. Science Education, 87, 849-867. http: / / dx.doi.org/10.1002/sce.10092

Myers, B., Latter, R., \& Abdollahi-Arena, M. K. (2006). The court of public opinion: Lay perceptions of polygraph testing. Law \& Human Behavior, 30, 509-523. http: / / dx.doi.org/ 10.1007/s10979-006-9041-0

Nehm, R., \& Reilly, L. (2007). Biology majors' knowledge and misconceptions of natural selection. BioScience, 57, 263-272. http:/ / dx.doi.org/10.1641/B570311

Owens, M., \& McGowan, I. W. (2006). Madness and the moon: The lunar cycle and psychopathology. German Journal of Psychiatry. Retrieved August 07, 2012 from http: / / www.gjpsy.uni-goettingen.de/gjp-article-owens.pdf

Phelan, J. C., Link, B. G., Stueve, A., \& Pescosolido, B. A. (2000). Public conceptions of mental illness in 1950 and 1996: What is mental illness and is it to be feared? Journal of Health and Social Behavior, 41(2), 188-207. http: / / dx.doi.org/10.2307/2676305

Piquette, J. S., \& Heikkinen, H. W. (2005). Strategies reported used by instructors to address student alternate conceptions in chemical equilibrium. Journal of Research in Science Teaching, 42, 1112-1134. http: / / dx.doi.org/10.1002/tea.20091

Pine, K., Messer, D., \& St John., K. (2001). Children's misconceptions in primary science: A survey of teachers' views. Research in Science \& Technological Education, 19, 79-96. http: / / dx.doi.org/10.1080/02635140120046240

Pohl, R. F. (Ed.). (2004). Cognitive illusions: A handbook on fallacies and biases in thinking, judgment, and memory. New York: Psychology Press

Posner, G. J., Strike, K. A., Hewson, P. W., \& Gertzog, W. A. (1982). Accommodation of a scientific conception: Towards a theory of conceptual change. Science Education, 66, 211-227. http:/ / dx.doi.org/10.1002/sce. 3730660207

Reif, F. (1995). Understanding and teaching important scientific thought processes. American Journal of Physics, 63(1), 17-32. http://dx.doi.org/10.1119/1.17764

Reiner, M., Slotta, J. D., Chi, M. T. H., \& Resnick, L. B. (2000). Naive physics reasoning: A commitment to substance-based conceptions. Cognition and Instruction, 18, 1-34. http: / / dx.doi.org/10.1207/S1532690XCI1801_01 
Ruble, R. (1986). Ambiguous psychological misconceptions. Teaching of Psychology, 13, 34-36. http:/ / dx.doi.org/10.1207/s15328023top1301_10

Schick, T., \& Vaughn, L. (2010). How to think about weird things: Critical thinking for a new age. Maidenhead: McGraw-Hill Higher Education.

Standing, L. G., Huber, H. (2003). Do psychology courses reduce belief in psychological myths? Social Behavior \& Personality, 31, 585-592. http: / / dx.doi.org/10.2224/sbp.2003.31.6.585

Stanovich, K. E. (2009). How to think straight about psychology (9th ed.). Boston: Allyn \& Bacon.

Stefani, C., \& Tsaparlis, G. (2009). Students' levels of explanations, models, and misconceptions in basic quantum chemistry. Journal of Research in Science Teaching, 46(5), 520-536. http: / / dx.doi.org/10.1002/ tea.20279

Stuart, H., \& Arboleda-Flórez, J. (2001). Community attitudes toward people with schizophrenia. Canadian Journal of Psychiatry, 46, 245-251.

Taylor, A. K., \& Kowalski, P. (2004). Naive psychological science: The prevalence, strength, and sources of misconceptions. Psychological Record, 54, 15-25.

Thompson, R. A., \& Zamboanga, B. L. (2003). Prior knowledge and its relevance to student achievement in Introduction to Psychology. Teaching of Psychology, 30, 96-101. http:/ / dx.doi.org/10.1207/S15328023TOP3002_02

Thompson, R., \& Zamboanga, B. (2004). Academic aptitude and prior knowledge as predictors of student achievement in introduction to psychology. Journal of Educational Psychology, 96, 778-784. http: / / dx.doi.org/10.1037/0022-0663.96.4.778

Treagust, T., \& Duit, R. (2008). Conceptual change: A discussion of theoretical, methodological and practical challenges for science education. Cultural Studies of Science Education, 3, 297-328. http: / / dx.doi.org/10.1007/s11422-008-9090-4

Vaughan, E. D. (1977). Misconceptions about psychology among introductory psychology students. Teaching of Psychology, 4, 138-141. http:/ / dx.doi.org/10.1207/s15328023top0403_9

Vosniadou, S. (2008). International handbook of research on conceptual change. London: Routledge.

Williams, R. L., Oliver, R., \& Stockdale, S. (2004). Psychological versus generic critical thinking as predictors and outcome measures in a large undergraduate human development course. Journal of General Education, 53(1), 37-58. http:/ / dx.doi.org/10.1353/jge.2004.0022

Winer, G. A., Cottrell, J. E., Gregg, V., Fournier, J. S., \& Bica, L. S. (2002). Fundamentally misunderstanding visual perception: Adults' belief in visual emissions. American Psychologist, 57, 417-424. http: / / dx.doi.org/10.1037/0003-066X.57.6-7.417

Winer, G. A., Cottrell, J. E., Karefilaki, K., \& Gregg, V. R. (1996). Images, words and questions: Variables that influence beliefs about vision in children and adults. Journal of Experimental Child Psychology, 63, 499-525. http: / / dx.doi.org/10.1006/jecp.1996.0060

Winer, G. A., Rader, A. W., \& Cottrell, J. E. (2003). Testing different interpretations for the mistaken belief that rays exit the eyes during vision. Journal of Psychology: Interdisciplinary and Applied, 137(3), 243-261. http: / / dx.doi.org/10.1080/00223980309600612

SEAN HUGHES ${ }^{\star}$ is a post-doctoral researcher at Ghent University, Belgium. His interests include Relational Frame Theory and its relationship to human learning, language and (implicit) social cognition. Correspondence: sean.hughes@ugent.be

FIONA LYDDY is a senior lecturer at the National University of Ireland, Maynooth. Research interests include student learning, communication, science literacy and numerical cognition.

SINEAD LAMBE is a trainee clinical psychologist at the University of Bath. Research interests include adult mental health, memory in depression, and psychosis.

${ }^{\star}$ Contact author.

Manuscript received 12 December 2011

Revision accepted for publication 17 September 2012 